\title{
Gender-biased sex selection in South Asia: The situation and promising approaches to restore balance
}

Population Council

Follow this and additional works at: https://knowledgecommons.popcouncil.org/departments_sbsr-pgy

Part of the Family, Life Course, and Society Commons, International Public Health Commons, Maternal and Child Health Commons, and the Women's Health Commons How does access to this work benefit you? Let us know!

\section{Recommended Citation}

Population Council. 2015. "Gender-biased sex selection in South Asia: The situation and promising approaches to restore balance," Project summary. New Delhi: Population Council. 


\section{GENDER-BIASED SEX SELECTION IN SOUTH ASIA: THE SITUATION AND PROMISING APPROACHES TO RESTORE BALANCE}

Sex ratios at birth in South Asia vary considerably. While the sex ratio at birth in Bangladesh and Pakistan, thus far, has been normal at country level (103 and 102.5 males per 100 females, respectively), Nepal is showing signs of disturbed sex ratios at birth, with a sex ratio of 106 males per 100 females (Central Bureau of Statistics, 2012), and the situation in India is particularly adverse, with a sex ratio at birth of 110 males per 100 females. In all of these countries, however, preconditions for a deterioration of the sex ratio at birth are evident. Preferences are expressed for small families, patriarchal social norms persist and societies tend to be gender-stratified with strong preferences for at least one son, and prenatal diagnostic techniques are widely available and used to monitor foetal development. Indeed, all four countries have long been characterised by wide gender disparities and a strong preference for sons, often manifested in terms of the greater investment in the health, nutrition and education of sons over daughters.

There are, however, within-country differences in sex ratios at birth and among children, including in Bangladesh and Pakistan, where overall sex ratios at birth remain normal. In Bangladesh, for example, skewed sex ratios at birth are observed in eastern/ central regions and normal ones in the neighbouring western region (NIPORT, Mitra and Associates and ICF International, 2013). In Pakistan, too, there are some settings in which adverse sex ratios at birth are evident; for example, Sindh has a higher than normal sex ratio at birth (National Institute of Population Studies and ICF International, 2013) and there is concern that adverse sex ratios at birth are also visible in some urban pockets. In Nepal, where skewed sex ratios at birth are evident at the national level, sub-national differences with unbalanced sex ratios have been observed in some districts in the Terai and hill regions but not in others in the same region (Central Bureau of Statistics, 2012). In India, which has had a far longer history of skewed sex ratios at birth, statewise differences are wide, ranging for example, from 103.5 in Kerala to above 118 males per 100 females in some states in the northwest, by 2002-04. Also notable in districts with particularly adverse sex ratios at birth and among children in the early 2000s, is evidence of improvements in the sex ratio at birth by 2011 in some districts but not in others in the same region (Office of the Registrar General, India, 2013).

Contextual differences must be noted. For example, while India and Nepal legally prohibit the disclosure of the sex of the foetus to guard against subsequent termination of pregnancies carrying a female foetus, Bangladesh and Pakistan have no such restrictions. Laws relating to termination of pregnancies, in general, also differ from relatively restricted in Pakistan to permitted under a host of reasons in India and Nepal, and permitted as menstrual regulation up to 10 weeks of gestation and somewhat restricted thereafter in Bangladesh. Also differing across countries have been programme responses to adverse sex ratios at birth and among children. As observed in the successful example of South Korea, it was a combination of enforcement of laws prohibiting gender-biased sex selection, the provision of educational entitlements and cash transfers for girls, and a strong community mobilisation programme intended to change norms about son preference and raise awareness about the law and the prohibition of gender-biased sex selection that was responsible for the rapid normalisation of the sex ratio at birth (Guilmoto, 2011). Of the four countries, it is in India where this multi-pronged response has been most concentrated - through 
the implementation of laws, as well as through programmes intended to build gender equity and raise the value of the girl child by way of educational entitlements and conditional cash transfers, and efforts to raise awareness and mobilise communities to both change norms related to son preference, and understand the dimensions of the law prohibiting disclosure of the sex of the foetus and subsequent termination of pregnancies carrying a female foetus. In other countries, the emphasis has been on efforts to build gender equity and raise the value of girls, through a diverse set of educational entitlements, conditional cash transfers and employment opportunities; in these settings efforts to reduce gender-biased sex selection, more specifically, are not present.

These widely differing scenarios raise different research questions for each setting. With support from UKAid, the Population Council's Bangladesh, India and Pakistan offices, and the Centre for Research, Environment, Health and Population Activities (CREHPA), Nepal, led by the Council's India office, undertook research that aimed to shed light on the issue of gender-biased sex selection in these countries and make evidence-based recommendations for actions that hold promise for responding to adverse sex ratios at birth in these settings. Given the wide contextual differences described above, a single research question across all four countries was not possible, and as such, specific objectives differed across countries: (a) In Bangladesh and Nepal, the objective was to explore programme and sociocultural factors underlying district-level differences in the sex ratio at birth or child sex ratio, by comparing the situation in districts with high sex ratios at birth and among children, respectively (Comilla in Bangladesh; Kaski in Nepal) and those with normal sex ratios (Rangpur in Bangladesh, Tanahun in Nepal); (b) in Pakistan, where evidence is extremely sparse and signs of imbalance in the sex ratio at birth very recent, to explore provider perspectives about the practice of gender-biased sex selection in urban pockets of Karachi, and (c) in India, to compare, in two settings of Haryana, a state with extremely adverse sex ratios at birth and among children, the programme and sociocultural factors underlying improvements in the sex ratio at birth in one district (Kurukshetra) from very adverse to somewhat less adverse in the 2001-2011 period, with a district in which sex ratios remained stagnant over the decade (Sonipat).
The study adopted a mixed method approach. In Bangladesh, India and Nepal, it included a survey of 1,000 or more married women with at least two children, one of whom was aged 0-5 years. In these countries, it also included key informant interviews with health care providers; and programme implementers from the public and NGO sectors. In Pakistan, where skewed sex ratios are not really observed, and evidence is sparse, only one component - key informant interviews with health care providers - was fielded. All four components were implemented in Bangladesh, Nepal and India. A common set of instruments was used; however, as noted above, certain issues that were not relevant in a particular country were omitted. The survey explored, from the perspective of women, family size desires, the strength of son preference, and the extent of disclosure of the sex of the foetus and termination of pregnancies carrying a female foetus; it also explored women's knowledge of the law, exposure to messages relating to raising the value of the girl child, in general, and addressing gender-biased sex selection, in particular. Where possible, primary research also explored the extent to which three types of programmatic interventions - law enforcement; communication, advocacy and community mobilisation efforts, and the provision of educational entitlements and conditional cash transfer programmes for girls - were implemented in each district, and the extent to which these interventions may have contributed to the different levels of sex ratios at birth and among children in contrasting districts of each country.

Annexure Tables 1 and 2 provide the key indicators obtained from the survey.

\section{Findings from Bangladesh and Pakistan where disclosure of the sex of the foetus is not legally restricted}

Bangladesh: Comilla and Rangpur were selected for the study based on their differing sex ratios at birth (117 and 105 males per 100 females, respectively). Findings highlight that although all three preconditions for skewing of sex ratios prevail in both districts, both use of ultrasonography, in general, and disclosure of the sex of the foetus, in particular, were more widespread in Comilla than Rangpur, with 65 percent of women from Comilla, compared to 51 percent from Rangpur having been informed about the sex of their foetus; however, termination of a pregnancy carrying a female foetus 
was reported by just one woman (out of 1,037), and women strongly opposed gender-biased pregnancy termination. Even so, son preference was evident in both districts, although more so in Comilla (the district with an adverse sex ratio at birth) than Rangpur (the district with a balanced sex ratio at birth). For example, the intention to have additional children was clearly related to the sex of living children among women in Comilla where women with more sons than daughters were more likely than those from Rangpur to report wanting no more children. Moreover, women in Comilla were also more likely to report disclosure of the sex of the foetus than were those in Rangpur, and such disclosure appeared to be contingent on the sex of the previous child. In Comilla, women at parity 2 whose first child was a daughter were more likely to have been informed about the sex of the second child than were women whose first child was a son. Furthermore, women's use of contraception was strongly associated with the sex composition of living children; in Comilla, women with two sons were 50 percent more likely to have been practising contraception than those with two daughters while in Rangpur, they were 20 percent more likely to have done so.

Factors underlying differences in sex ratios at birth between the two districts were explored. Differences in the implementation of laws and programmes were typically moderate. For example, with regard to educational entitlements and conditional cash transfer programmes, notably school stipends for girls, differences were mild although access to these programmes was more likely to be reported by women from Rangpur than Comilla. Programme implementers were, moreover, optimistic that stipends, microfinance and employment opportunities in the apparel industry played a powerful role in changing attitudes about girls and raising their status, but were sceptical about whether these programmes could change preferences for sons over daughters. With regard to communication, advocacy and community mobilisation programmes, programme implementers from public as well as NGO sectors confirmed that programmes focusing on genderbiased sex selection or sex-selective abortion are not implemented in study districts or, more generally, in the country. However, they acknowledged that programmes that focus on non-discrimination against daughters are widely implemented, and while these take place in both districts, findings indicate that they are more prevalent in Comilla than Rangpur, confirming perhaps, that these programmes were more likely to be implemented in districts with high levels of discrimination. Finally, with regard to the implementation of laws, even though there is no law prohibiting the disclosure of the sex of the foetus, key informants, mainly health care providers from both districts, acknowledged that laws relating to abortion are poorly enforced and monitored, and that programmes do not exist that inform health care providers about misuse of technology for genderbiased sex selection. Roughly, 40 percent of women - particularly those in Comilla - expressed a need, moreover, for a law on gender-biased sex selection, suggesting perhaps, that the practice is not entirely absent in the district.

Overall, districtwise differences in programme implementation were mild, and findings suggest that while the potential does indeed exist for gender-biased sex selection and the termination of pregnancies carrying a female foetus, differences in sex ratios at birth in Comilla and Rangpur may also be attributed to different family-building strategies. The authors note that women from Comilla, compared to those from Rangpur, were more likely to base their childbearing strategies on the number of sons they had, in that they were more likely to stop childbearing as soon as they had their desired number of sons; in Rangpur, in contrast, childbearing was more likely to stop when the desired family size was achieved. The authors suggest that differential 'stopping' strategies (for family size limitation) may play a role in accounting for differences between the two districts, but note that the potential exists, particularly in Comilla, for following disclosure of the sex of the foetus with the termination of pregnancies carrying a female foetus, especially in view of the fact that violation of the abortion law relating to the termination of pregnancies beyond the prescribed gestation period is rarely punished.

Pakistan: Major Urban Sindh, in which Karachi is located, reports a sex ratio at birth of 107.5 compared to 102.5 males per 100 females in Pakistan as a whole. Our study focused on understanding the perspectives of some 15 health care providers, selected to represent the array of providers serving women's reproductive health in the city, about this incipient increase in the sex ratio at birth in Karachi. Findings highlight that providers, ranging from mid-level providers to obstetrician-gynaecologists, were largely unaware that the sex ratio at birth was unbalanced in Karachi. Nevertheless, they confirmed 
that preconditions for skewing of sex ratios did indeed prevail in Karachi. For example, they acknowledged the persistence of son preference and observed that women with sons were better treated than those with only daughters, and emphasised the existence of a huge demand for the disclosure of the sex of the foetus, albeit largely for reasons that excluded gender-biased sex selection. Indeed, they emphasised that disclosure of the sex of the foetus was not against the law, but admitted that while abortion is legally restricted, laws are poorly enforced. Even so, most providers believed that sex-selective abortions were unlikely to be performed, because disclosure of the sex of the foetus via ultrasonography takes place only at 16-18 weeks and even though the law is poorly enforced, abortions at $16-18$ weeks are almost impossible to obtain. At the same time, however, at least one of 15 providers was familiar with the practice of sex-selective abortion, and several reported that they were aware of providers and facilities that refused to reveal the sex of the foetus, suggesting again that the practice does take place. The authors conclude that there is indeed potential for increased resort to pregnancy termination following disclosure of a female foetus.

\section{Findings from Nepal and India where disclosure of the sex of the foetus is legally restricted}

Nepal: Kaski and Tanahun districts were selected for the study based on their differing child sex ratios (114 and 102 males per 100 females, respectively). Findings highlight that son preference is widespread, and, perhaps most revealing, disclosure of the sex of the foetus was reported by more than one in four women who had given birth in the five years preceding the survey, despite laws prohibiting such disclosure. Districtwise differences in both indicators were evident: the importance of at least one son was far more likely to be articulated by women from Kaski, the district with distorted sex ratios than Tanahun, the district with balanced sex ratios, and more women from Kaski than Tanahun (37\% versus 27\%) reported that they had been told the sex of their foetus. Besides, proportions reporting being so informed, increased systematically with parity, and in Kaski, in particular, disclosure was greater if the previous child was female than if it were male. Finally, far more women from Kaski than Tanahun reported that they themselves or someone they knew had experienced a sex-selective abortion (31\% versus 15\%).
In order to explore factors underlying districtwise differences in these practices, researchers explored the extent to which differences emerged in terms of the spread of educational entitlements and cash transfers for girls; access to communication, advocacy and community mobilisation, and implementation and awareness of the law on disclosure of the sex of the foetus and sex-selective abortion, as well as certain sociocultural factors that set each district apart. Findings suggest that school-based entitlements, including scholarships were accessed in both districts but significantly more so in Tanahun than Kaski (37\% versus $25 \%$ of women with eligible daughters); as in Bangladesh, programme implementers noted that while educational entitlements played a powerful role in empowering girls and reducing child marriage, they were unlikely to affect parents' desire for at least one son. As far as the implementation of laws was concerned, programme implementers were more likely than health care providers to report awareness of law enforcement activities; findings suggest that the law was rarely enforced, neither inspections nor raids had taken place anywhere, and corruption was observed in both districts. Even so, programme implementers from Tanahun were somewhat more likely than those in Kaski to report that district public health staff played an active role in law enforcement and monitoring of facilities. Finally, communication, advocacy and community mobilisation activities focusing on raising the value of girls, were prevalent in both districts, and while differences were largely narrow, women from Kaski were more likely to have been exposed to media messages, and those from Tanahun to interpersonal communication delivered by frontline workers, NGO programmes and religious leaders.

In short, while differences between the two districts were relatively mild, laws appeared to be better implemented, educational entitlements for girls better utilised, and exposure to interpersonal communication was more evident in Tanahun than Kaski. At the same time, the role of structural factors cannot be ignored. For example, key informants raised such issues as differences in prevailing caste compositions, with those in Kaski maintaining a stronger preference for sons than those in Tanahun; some also highlighted that the stronger son preference displayed by women from Kaski was linked to parents' aspirations for upward mobility, notably via the employment of sons in the British Army. Most evident were differences in such structural factors as 
poverty levels, availability of ultrasonography facilities, equipment and trained personnel, and distances to available facilities, with Tanahun far more disadvantaged on all of these factors than Kaski. These findings clearly point to the potential for the spread of gender-biased sex selection once services are more easily and cheaply available.

Haryana, India: India has had a much longer history of distorted sex ratios at birth, a law that strongly prohibits gender-biased sex selection, and a more diverse set of interventions intended to restore balance in the sex ratio at birth. Although Haryana remains one of the worst affected states, over the decade 2001 to 2011, modest but noticeable improvements have taken place in the sex ratio at birth in some districts, such as Kurukshetra (from 128.5 to 122.3), but not in others, such as Sonipat (from 124.2 to 124.1). Findings highlight that the small family norm is widespread, as is son preference; disclosure of the sex of the foetus, possibly under-reported, was acknowledged by small proportions of women, with more women experiencing their third pregnancy from Sonipat so reporting than those from Kurukshetra (6\% versus 2\%), and more women from Sonipat than Kurukshetra reporting that they or someone they knew had been told the sex of their foetus (23\% versus 16\%). While just 3-4 percent of women from both districts who had undergone an abortion reported they had done so for sexselective reasons, key informants, mainly health care providers and NGO programme implementers, from the two districts estimated that between one and fifty percent of pregnant women were likely to have done so.

In order to explore factors likely to have contributed to the improvement in sex ratio at birth in Kurukshetra, we explored the extent to which differences emerged in terms of the spread of educational entitlements and conditional cash transfers for girls; implementation and awareness of the law on disclosure of the sex of the foetus and sex-selective abortion, and implementation of and exposure to communication, advocacy and community mobilisation activities. As far as educational entitlements and conditional cash transfers are concerned, similar proportions of women reported accessing school-related entitlements and enrolling their daughters in the Ladli Scheme, a conditional cash transfer scheme for girls. As in the case of other countries, however, programme implementers from public and NGO sectors from both districts, warned that while such schemes and educational entitlements would contribute to increased educational attainment and delayed marriage among girls, it may not, at least in the near future, affect son preference or gender-biased sex selection. With regard to the implementation of the PCPNDT Act also, interdistrict differences were not observed: relatively few women had heard about doctors being prosecuted or clinics closed (41-42\%) or had heard about raids (21-26\%) taking place in their district. Key informants from all three categories and from both districts described such measures taken to implement the Act as inspections and raids, maintenance of detailed records of women and tracking of pregnant women, prosecution of violators, suspension of licences, sealing of equipment and facilities, and imposition of fines, but also described such challenges as the absence of prosecution, in fact, of women and families who, in seeking disclosure of foetal sex, violated the Act just as did service providers (reported by health care providers and a few public sector programme implementers); excessive paperwork and harassment of honest providers (reported by health care providers; poorly trained law enforcement officials, and the undue burden placed on state and district health authorities to implement the Act (reported by public sector programme implementers), and interference by political leaders and other influential individuals to protect certain providers (all three categories of key informants, but mainly public sector and NGO programme implementers).

Interdistrict differences were more pronounced in the case of communication, advocacy and community mobilisation. More women from Kurukshetra than Sonipat were aware of the Act, although similar and large proportions had been exposed to messages about the prohibition of disclosure of the sex of the foetus and about raising the status of girls. Notably, far more women from Kurukshetra than Sonipat had been exposed to interpersonal communication, for example, counselling by a frontline health worker (31\% versus $23 \%$ ), and discourses by religious leaders discouraging gender-biased sex selection (20\% versus $14 \%$ ). Moreover, interviews with public sector programme implementers revealed the far greater involvement of the public sector in communication, advocacy and community mobilisation activities in Kurukshetra than in Sonipat. Indeed, in Kurukshetra, weekly Night Halt or Open Durbar programmes were implemented by public 
sector programme implementers at village level, monthly visits were made to schools and colleges where oath-taking ceremonies were undertaken to build commitment among students and teachers about gender equity and desisting from gender-biased sex selection.

In addition, some key informants, raised two additional factors they believed accounted for differences between the two districts: Sonipat's greater proximity to Delhi and Uttar Pradesh, where, they believed gender-biased sex selection was more freely available than in Haryana, reported mainly by health care providers and public sector programme officials, and the dominant caste composition of the two districts, with a concentration of more gender inegalitarian castes in Sonipat than Kurukshetra, reported by a few public sector programme implementers. We emphasise that both of these factors reflect the perceptions of certain key informants, and others have dispelled these opinions, noting for example that mere geographic distance cannot inhibit a determined woman from accessing services, and that there is a danger in stereotyping castes as gender inegalitarian.

\section{Lessons learned and way forward}

The findings of our studies are by no means conclusive, but provide a range of insights into both the potential for change in sex ratios at birth and among children on the one hand, and what works to improve these ratios, on the other.

For one, findings have stressed that disclosure of the sex of the foetus does take place in all four countries. The practice appears to have little effect at present on subsequent termination of pregnancies carrying a female foetus in Bangladesh and Pakistan, where disclosure is not against the law. While fewer women in India and Nepal, where disclosure is prohibited by law, reported such disclosure, the practice was revealed by considerably more women in Nepal where disclosure of the sex of the foetus has become prevalent, particularly in the district in which the sex ratio at birth is unbalanced, but also in the district in which the sex ratio at birth is currently unaffected, suggesting that no district of Nepal is immune from the risk of a worsening of sex ratios at birth, and reflecting, perhaps, the effect of the concerted efforts made in Haryana to halt the practice, and the relatively limited priority accorded to the skewing of sex ratios at birth in Nepal.
Second, findings from Bangladesh, Nepal and even Pakistan, highlight that the potential for greater resort to gender-biased sex selection and sex-selective abortion does exist, given persistent son preference and poor implementation of laws intended to prevent such practices. Indeed, as likely in Nepal, it may be structural factors - poverty, lack of access to diagnostic facilities - that have impeded access to gender-biased sex selection in districts in which ratios are currently balanced, rather than specific efforts to ensure that the practice is not undertaken. As such, with the proliferation of diagnostic centres and better-trained providers, the likelihood of the practice of disclosure of the sex of the foetus and subsequent termination of pregnancies carrying female foetuses may increase even in poorer districts, as witnessed historically in Haryana and other parts of India, unless balancing measures are put in place.

With regard to what works, findings have shown that the full array of interventions - implementation of laws, provision of educational entitlements and conditional cash transfers for girls, and communication, advocacy and community mobilisation efforts to change gender inegalitarian norms and discourage gender-biased sex selection - was implemented only in Haryana. Even so, some commonalities were observed. For example, key informants (largely programme implementers) expressed a belief that while educational entitlements (Nepal) and both educational entitlements and conditional cash transfer programmes (Bangladesh and India; conditional cash transfer programmes are not implemented in Nepal) for girls were effective in enhancing girls' access to education and delaying their marriage, they were unlikely to influence parents' willingness to have a (higher order) daughter or an only-daughter family in the short run, although their longer term impact should not be discounted. Findings from Nepal and Haryana have also indicated the huge challenges that prevail in implementing their respective laws prohibiting disclosure of the sex of the foetus.

Perhaps the most promising programme-related finding, observed consistently in both Haryana, India, and Nepal, is the importance of communication, advocacy and community mobilisation efforts. Evidence from Nepal highlights the role of interpersonal communication delivered by frontline workers, NGO programmes and religious leaders that focused on raising the status of girls. From 
Haryana, India, the evidence is even stronger: interpersonal communication by frontline workers, exposure to discourses by religious leaders, regular efforts made by public sector programme implementers to connect with communities at the village level as also with schools and colleges, on a regular basis, to change norms and attitudes and raise awareness about the law, clearly distinguished the district in which improvement in the sex ratio at birth was observed from the one in which no such change was evident. Our findings, thus, offer tentative support to the conclusion that while educational entitlements for girls and implementation of the law are important, concerted efforts towards communication, advocacy and community mobilisation are essential to transform gender norms and discourage gender-biased sex selection.

\section{References}

Central Bureau of Statistics. 2012. National Population and Housing Census 2011 (National Report). National Planning Commission Secretariat, Government of Nepal: Kathmandu.

Guilmoto, C.Z. 2011. Sex Imbalances at Birth: Trends, Consequences, and Policy Implications. Accessed on 1 July, 2015 , at http://www.unfpa.org/sites/default/files/resource-pdf/Guilmoto_Revised_presentation_Hanoi_Oct2011.pdf

National Institute of Population Studies (NIPS) [Pakistan] and ICF International. 2013. Pakistan Demographic and Health Survey 2012-13. Islamabad, Pakistan, and Calverton, Maryland, USA: NIPS and ICF International.

National Institute of Population Research and Training (NIPORT), Mitra and Associates and ICF International. 2013. Bangladesh Demographic and Health Survey 2011. Dhaka, Bangladesh and Calverton, Maryland, USA: NIPORT, Mitra and Associates and ICF International.

Office of the Registrar General and Census Commissioner, India. 2013. Census of India 2011: Primary Census Abstract, Data Highlights, India, Series 1. New Delhi: Office of the Registrar General and Census Commissioner, India. Accessed on 25 March, 2014 athttp://www.censusindia.gov.in/2011census/PCA/PCA_Highlights/pca_highlights_file/India/Chapter-1.pdf 


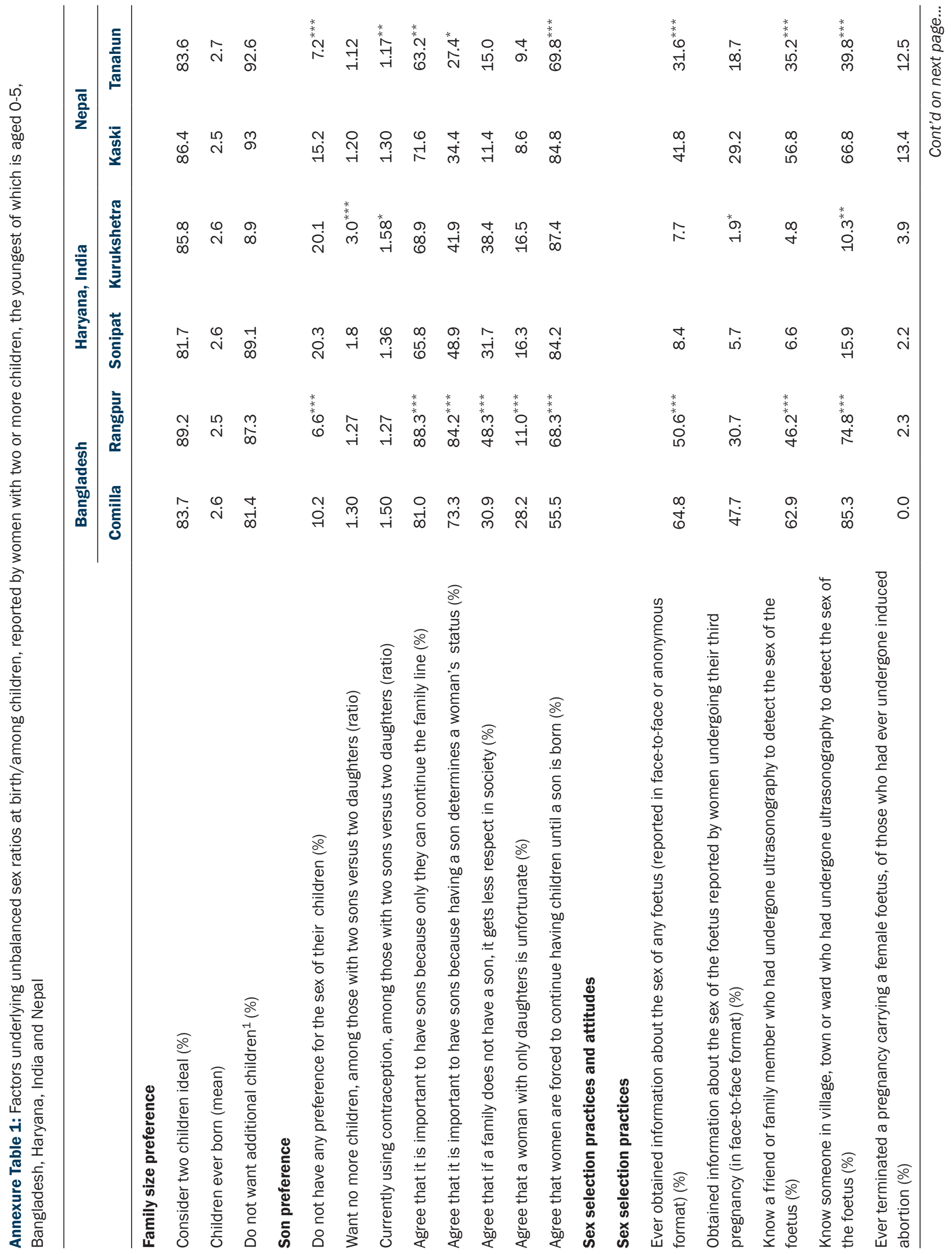




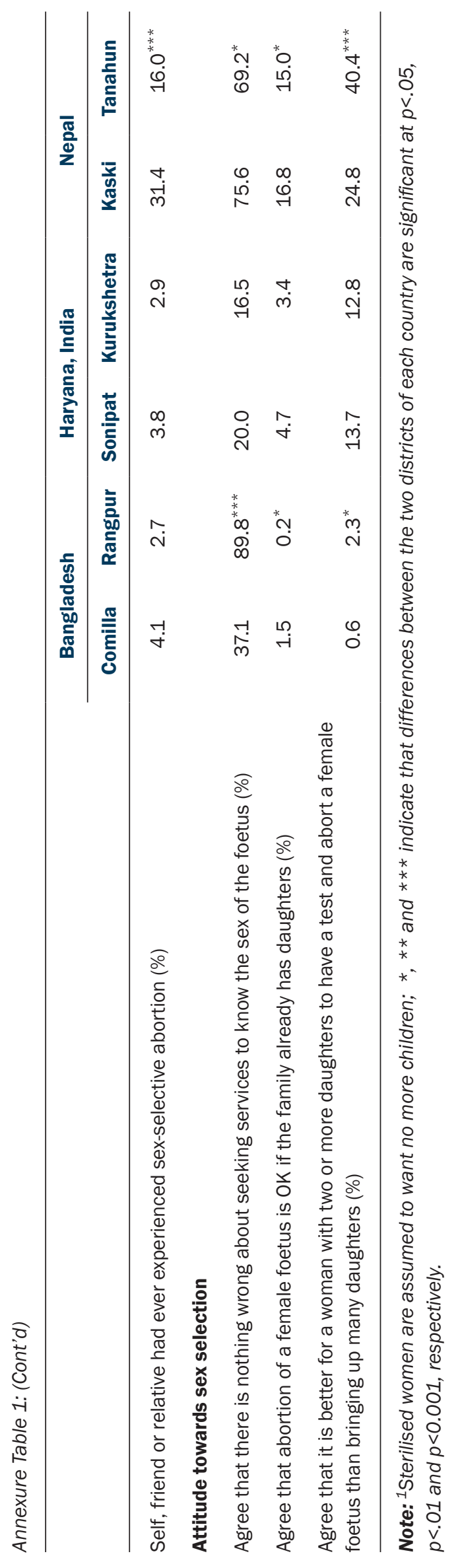




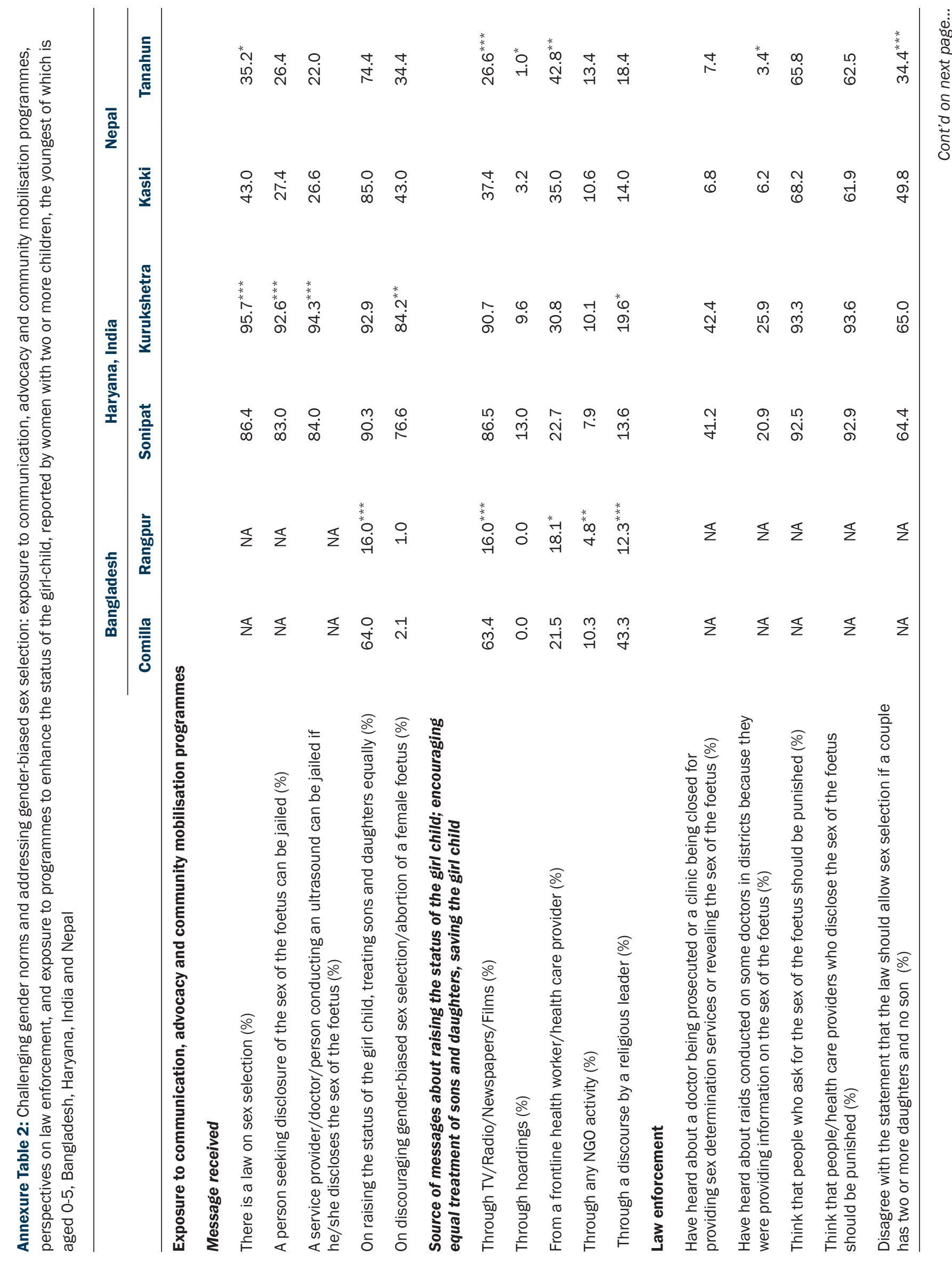




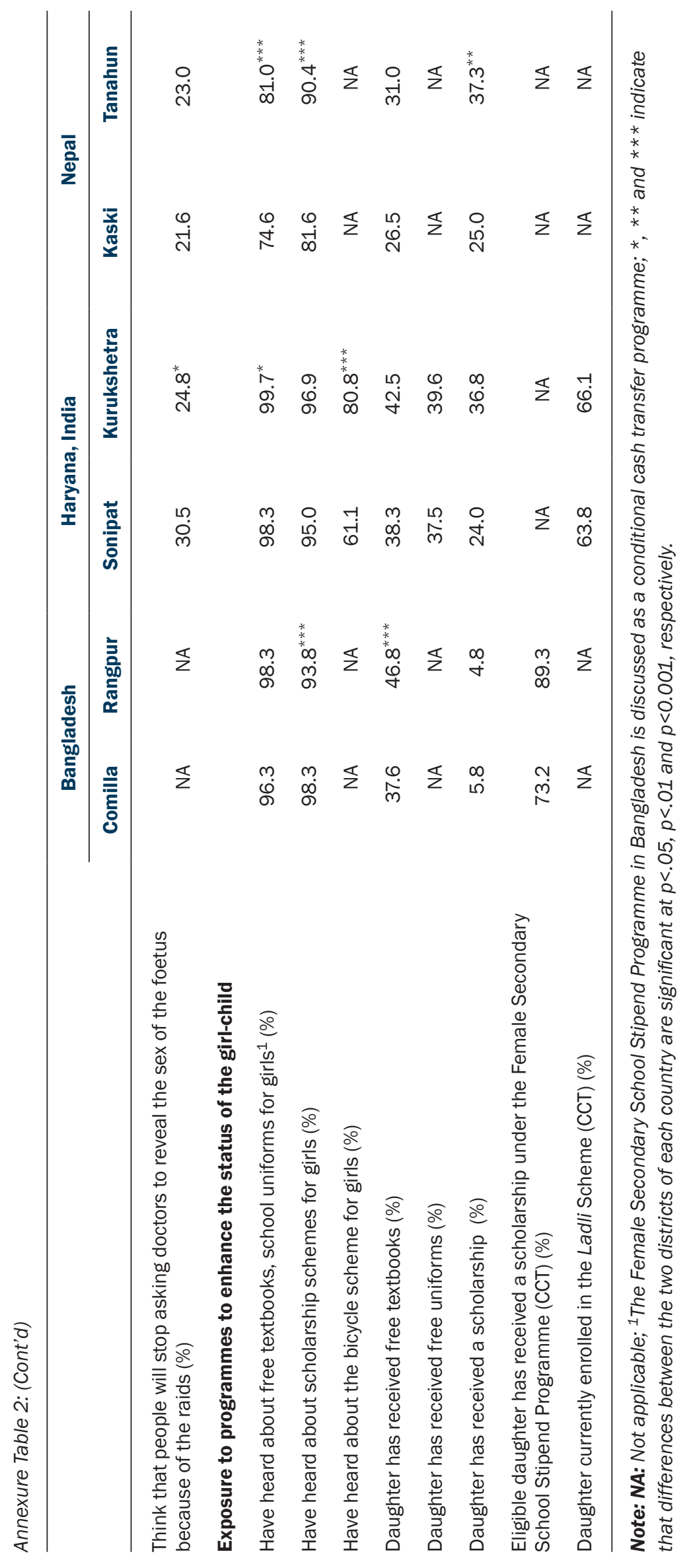




\section{Study teams}

\section{Bangladesh}

Ubaidur Rob

Noorunnabi Talukder

Population Council, Dhaka

\section{India}

Shireen J Jejeebhoy

Rajib Acharya

Sharmistha Basu

AJ Francis Zavier

Population Council, New Delhi

\author{
Nepal \\ Mahesh Puri \\ Anand Tamang
}

CREHPA, Kathmandu

\section{Pakistan}

Zeba Sathar

Gul Rashida

Ali Mir

Population Council, Islamabad
POPULATION

COUNCIL

Ideas. Evidence. Impact.

The Population Council confronts critical health and development issues-from stopping the spread of HIV to improving reproductive health and ensuring that young people lead full and productive lives. Through biomedical, social science, and public health research in 50 countries, we work with our partners to deliver solutions that lead to more effective policies, programs, and technologies that improve lives around the world. Established in 1952 and headquartered in New York, the Council is a nongovernmental, nonprofit organization governed by an international board of trustees.

\section{क्रपा CREHPA}

Established in July 1994, Center for Research on Environment Health and Population Activities (CREHPA) is a not-for-profit research organization based in Kathmandu, Nepal. The organization conducts policy relevant research on population, reproductive and sexual health and rights including on genderbased violence in collaboration with government ministries, universities, bilateral, multi-lateral agencies and international non-governmental organizations. Results of policy research are disseminated widely and utilized for advocacy to influence law and policy decisions.

\section{NVL \\ TAN \\ UKaid}

This project has been funded by UKaid from the UK Government; however the views expressed do not necessarily reflect the UK Government's official policies. 